Elisabeth Fertig

\title{
Translator's Reflection
}



Ballad of Three Important Men is a "Hörspiel" by the Nobel-Prizewinning Austrian poet, essayist, novelist, and playwright Elfriede Jelinek, originally titled Für den Funk dramatisierte Ballade von drei wichtigen Männern sowie dem Personenkreis um sie herum, and written for broadcast on German radio in 1974. "Hörspiel" (plural "Hörspiele") is a word I intentionally leave untranslated. In more or less literal terms, it means something like "hearing play," but that doesn't quite capture the full meaning. Though its closest equivalent in Anglophone literature is the radio play, the Germanophone Hörspiel is historically and aesthetically distinct from its nearest counterparts in other language traditions. To this day, many well-known German and Austrian writers have had Hörspiele produced on the radio, often written in the early stages of their careers and thus influencing their later work. The Hörspiel is regarded as a major literary genre and encompasses a rich tradition of audio-poetic innovation and experimentation, whose mediaspecific themes and methods can be seen to have flowed back into German literary aesthetics in general.

Chief among the many challenges of this project was the deceptively simple question: What exactly is the source text of a Hörspiel translation? In other words, when translating a literary genre whose primary form is the acoustic event of a radio broadcast, where do we locate the work? To admit that the answer to this question is not immediately obvious, more than just presenting a technical obstacle, can also open space for literary- and media-theoretical contemplation, as well as illuminate provocative questions about the nature of translation. Typically, a Hörspiel begins as a script-words on a page - which may be either published in book form or may be available to researchers only as a manuscript in an archive, if at all. In this case, I've relied on a script of Ballade published in 1980 by the press of a small art gallery near Munich called Kunstraum Schwifting. Along with this text, I've worked with an archival mp3 recording of the 1974 premiere production on West German radio, running just over 45 minutes long. This audio production diverges from the script in interesting ways. For example, the production rearranges the script substantially-even changing the order of certain scenes. Why was this done? Was it to accentuate the impact or increase the 
legibility of the "voice swap" scenes, where the male and female voice actors suddenly switch roles? In the use of music and sound effects, while following the stage directions in the script, the production also makes notable interpretive choices; for example, the recurring musical motif of the theme from Swan Lake is sometimes distorted, looped, or abruptly started and stopped at full volume without fading, rendering it uncanny and sinister and underscoring the sense of entropy that animates the piece.

Finally, in the cryptic last monologue, spoken by the characters identified as male voice 1 and male voice 2 , the stage directions indicate only that the voices should "repeat and gradually fade out," but in the recording there is much more going on. The first time they speak the line, the voices take turns. Then they begin to chant in unison, and each time they repeat the line, their voices get just a little louder, a little faster, and a little angrier. By the end, we hear them practically screaming the words, just as the prescribed fade-out begins to mute their impotent rage. Provisionally, prioritizing readability, I've left such production choices largely undocumented in my translation, with a few exceptions. But one can equally imagine an alternative or future version of this project that uses the recording, and not the script, as its primary source text. How might the translator choose to represent in written form what in the source work is not read, but heard? Perhaps the proper form for this translation would not be a printed text at all, but a radio production.

In asking questions like these, we might notice that a production of a Hörspiel is already a sort of translation: the director, producer, composer, voice actors, engineers, editors, etc., are the translators who take the author's written source text and convert it from a work of written language into an acoustic text, from the medium of print into radio. In this respect, the Hörspiel bears much in common with adjacent forms like stage drama, and especially with film and television, though it is distinct in that its action unfolds purely in the acoustic realm, and its associated conventions for criticism and academic study are less well established. As with any work of translation, there is no single or straightforward way to go about it: even a script with the most abundant and detailed stage directions must be interpreted. The dream of a "faithful" interpretation of the script, 
as with any translation, ultimately reveals itself as a utopian or even authoritarian fantasy: even where the production follows the script as closely as possible, it is constructed from a series of choices and takes on a life over and above the text on which it is based. In fact, Jelinek is famous for leaving production details up to the director's interpretation, especially in her stage dramas, as indicated by her iconic stage direction: "machen Sie was Sie wollen" ["do what you want"]. This move not only emphasizes the inherently translational nature of performing a written script but helps destabilize the traditional categories of author and work entirely, opening out onto a fundamentally dynamic and collaborative conception of the text.

There is another major aspect of this piece that comes across more fully in the audio production than in the written script: it's funny. Harsh critics of Jelinek's often shockingly grotesque poetics tend to miss the comic or satiric register, maybe owing in part to the inevitable translation problems and lack of familiarity with the historical Austrian context with which she's in conversation. But in working on this project and in the frame of my larger dissertation research on the Hörspiel, I have come to believe that Jelinek's humor, like her language in general, reaches its most profound unfolding when performed. I read the script first, but it was only while listening to the audio that I laughed out loud.

The most obvious source of humor in this Hörspiel is the confusion caused by the increasingly denaturalized gender relationships initially set in motion by the "voice swap." However, it's my sense that the awkward, stilted dialogue is the bedrock on which the rest of the comedy builds. The characters parrot stock phrases, repeat themselves ad absurdum, blurt out song titles and generally sound unnatural. In this translation, I've sought to at least preserve and at times even amplify this effect. For instance, I chose to translate the out-of-place song titles more or less literally into English, rendering them all the more strange. I hope that readers (especially first-time readers of Jelinek) will have patience with the range of negative affects-from confusion to irritation to fatigue to revulsion-that wading through such alienated language might elicit. I believe there is value in staying with the discomfort of a disorienting aesthetic encounter like this one. A funny thing can happen when reading 
any text in translation, as when speaking a foreign language: the illusion of smoothness and sense more readily falls away, exposing the ideological trusswork holding idiomatic language together. The weirdness that ensues can be a punchline and epiphany at once. If you get stuck, I recommend reading it aloud. 